\title{
How Important is the Intermediate Input Channel in Explaining Sectoral Employment Comovement over the Business Cycle?
}

\author{
K. Kim ${ }^{a}$ and Y.S. Kim ${ }^{b}$

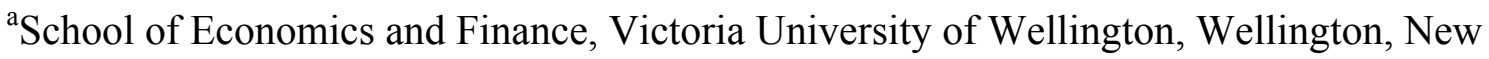 \\ Zealand \\ ${ }^{\mathrm{b}}$ Department of Economics, Kyung Hee University, Seoul, Korea
}

April, 2003

\begin{abstract}
This paper studies a multisector dynamic stochastic general equilibrium model calibrated to the 2-digit SIC level intermediate input-use and capital-use tables to investigate the importance of the intermediate input channel in explaining the sectoral employment comovement over the business cycle. In general, the business cycle comovement in employment depends on preferences as well as technology with intersectoral linkages. With indivisible labor implying that consumers do not care about the variability of leisure, the intersectoral linkages at a disaggregated level are sufficient to generate the strong business cycle comovement across sectors. With divisible labor, however, leisure-smoothing effect can dominate a sector's intersectoral linkages, implying a negative comovement. It further requires some form of worker's reluctance to substitute labor hours across sectors. Referring to some micro-level studies on the low wage elasticity of labor supply, a low substitution of labor hours is shown to generate the strong business cycle comovement in sectoral hours worked.
\end{abstract}

Keywords: Intermediate input channel; Sectoral employment comovement; Multisector dynamic stochastic general equilibrium model 


\section{INTRODUCTION}

It is well known that, over the business cycle, most sectors of the economy move up and down together. This comovement is a central part of the definition of the business cycle. Under the National Bureau of Economic Research's (NBER) definition, for example, "a recession is a period of decline in total output, income, employment, and trade, usually lasting from six months to a year, and marked by widespread contractions in many sectors of the economy." More recently, Christiano and Fitzgerald (1998) document substantial business cycle comovement for hours worked across sectors in the US.

Over the last two decades, however, macroeconomists have mainly focused on understanding the persistence and volatility in the cyclical fluctuations of aggregate economic data. Standard models of business cycles such as Kydland and Prescott (1982) and King et al. (1988), consider a single sector economy to examine the ups and downs of aggregate economic activity. For the obvious reason, these models are not useful to explain a key defining characteristic of the business cycle: the comovement of economic activity across many sectors.

Motivated by the observation that some of the output of the nondurable goods sector is also used as intermediate goods in the production of durable (investment) goods, Hornstein and Praschnik (1997) modify a standard real business cycle model to accommodate this "intermediate goods channel" of the economy. During a boom, this has the effect of increasing the value of output in the nondurable (or consumption) sector with the increased need for its output for use in the investment sector. With indivisible labor and perfectly mobile labor across the two sectors, their model generates strong contemporaneous correlation for sectoral employment.

However, the Hornstein-Praschnik's two sector model is not consistent with the observed comovement in investment across sectors. Christiano and Fitzgerald (1998) also examine data on the subsectors of the nondurable goods sector and note the "weak" relationship between employment comovement and the intermediate goods channel, measured as the fraction of a nondurable sector's gross output which is used as intermediate goods sent for the production of final investment goods. In order to further explore the role of the intermediate goods channel in accounting for comovement of employment and investment across sectors, we consider a much broader intermediate goods channel which allows for the potential uses of a sector's output (nondurable or durable) as intermediate inputs and/or capital inputs in the production of nondurables or durables (including final investment goods).

More specifically, this paper is to investigate the importance of the intermediate goods channel in the context of a multisector dynamic stochastic general equilibrium model with more disaggregated production sectors. Very recently, Horvath $(1998,2000)$ have developed a generalized version of Long and Plosser (1983). Calibrated to the 2-digit Standard Industrial Code (SIC) level of disaggregation (using the intermediate input-use and the capital-use matrices), it shows that the model can match aggregate fluctuations in the US with independent sectoral shocks only. However, Horvath (2000) focuses only on 
the issue of understanding the persistence and volatility in aggregate fluctuations along with the relative volatilities of sectoral fluctuations, ignoring the synchronized nature of economic activity (e.g., employment comovement) across sectors.

In order to examine the significance of the disaggregation level in Hornstein and Praschnik (1997) (which assume only two sectors, nondurable and durable), we first examine an indivisible-labor version of Horvath (2000) calibrated to the 2-digit SIC level (e.g. 36 sectors) of the intermediate input-use and the capital-use tables. The model simulations yield strong sectoral employment comovement over the business cycle. With indivisible labor implying that consumers do not care about the variability of leisure, sectoral employment depends largely on its output which can be potentially allocated to the following three uses: intermediate inputs in the industrial sectors, investment goods built into the capital stocks of the sectors, and final consumption goods. Therefore, as long as both the intermediate input-use and the capital-use matrices at a disaggregated level indicate sufficiently strong intersectoral linkages, sectoral employments tend to comove over the business cycle. The model simulations show that the intersectoral linkages in the actual data are strong enough to generate the employment comovement. Moreover, the intersectoral linkages are consistent with the comovement in investment across sectors, although its size is below the actual one.

Although these findings are qualitatively similar to those in Hornstein and Praschnik (1997), the sectoral comovement in employment depends crucially on the indivisiblelabor specification of preferences. With divisible labor or leisure-smoothing in the sense that consumers prefer a less variable leisure, a given sector's hours worked are negatively related to those in the other sectors. Hence, for those sectors whose output is sent trivially for the inputs in the production sectors, the intersectoral linkages can be dominated by the "leisure-smoothing" effect, yielding negative employment comovement.

Noting the low wage elasticity of labor supply and persistent wage differences across sectors, we simulate a divisible-labor version of Horvath (2000) where elasticity of substitution of labor supply is relatively low across sectors.

An interpretation of this specification is that the representative worker/consumer has a preference for diversity of labor hours despite wage differences across sectors. This modification is analogous to Boldrin et al. (1999) which assume limited labor mobility between industry sectors, although they require additional restriction on preferences in the form of habit persistence to guarantee comovement. We find that, as long as the elasticity of substitution of labor across sectors is sufficiently small, the multisector model calibrated to the 2-digit SIC level of disaggregation (i.e. 36 sectors) can generate the observed strong comovement of sectoral hours worked. Therefore, in the presence of the wide variation in the fraction of a given sector's output channeled (as intermediate inputs and capital goods) to the production processes of many other sectors, the intermediate channel is not sufficient to generate the strong business cycle comovement across sectors: it further requires some form of worker's reluctance to substitute hours worked across sectors. 
The paper is organized as follows. Section 2 describes the model economy and the definition of competitive equilibrium, followed by the model calibration as in Horvath (2000). Section 3 presents simulation results on the business cycle comovement of sectoral hours worked. Section 4 summarizes the paper.

\section{THE MODEL}

In order to examine the significance of the intermediate-goods linkages in the business cycle comovement, we first generalize Hornstein and Praschnik (1997)'s two-sector dynamic stochastic general equilibrium model to 36 sectors at the 2-digit SIC level of disaggregation whose sectoral linkages are calibrated to the intermediate input-use and the capital-use tables.

\subsection{The Environment}

The model economy consists of $M$ (say, 36) distinct sectors, indexed by $h=1,2, \ldots, M$, each producing a different good. The technologies are distinct across the sectors. Multifactor productivity in each sector is subject to stochastic innovations which are not perfectly correlated across sectors. The output of each sector goes to potentially three different uses. First, some goods are used as intermediate inputs in the production of other goods and sectors do not necessarily use the same intermediate inputs. Second, some goods are built into the capital stocks of the sectors in the economy and each sector has a distinct capital stock. Finally, a portion of output in each sector is supplied to a final consumption market. It is assumed that intermediate inputs are delivered and either used within one period or built into the capital stock of the purchasing sector. The production of each sector is controlled by firms which operate so as to maximize their expected present discounted value to shareholders.

An output, $y_{t}^{h}$, of good $h$ is produced by combining capital in the sector, $k_{t}^{h}$, labor, $n_{t}^{h}$, and an index of intermediate inputs, $M^{h}$ in a production process given by

$y_{t}^{h}=A_{t}^{h}\left(k_{t}^{h}\right)^{\alpha_{h}}\left(n_{t}^{h}\right)^{\beta_{h}}\left(M_{t}^{h}\right)^{\gamma_{h}}$,

where constant returns to scale implies $\alpha_{h}+\beta_{h}+\gamma_{h}=1$. In (1), $A_{t}^{h}$ represents the multifactor productivity or state of technology in sector $h$, which is assumed to follow a stochastic process given by

$A_{t}^{h}=\rho A_{t-1}^{h}+\varepsilon_{t}^{h}$ 
where $\varepsilon_{t}^{h}$ is a serially uncorrelated, normally distributed random variable with mean zero and $E\left(\varepsilon_{t} \varepsilon_{t}^{\prime}\right)=\boldsymbol{\Omega}$.

The index of intermediate inputs for sector $h$ has a Cobb-Douglas form which implies a unitary elasticity of substitution between inputs:

$M_{t}^{h}=\prod_{s \in B_{h}^{M}}\left(m_{t, s}^{h}\right)^{x_{s h}}$

where $m_{t, s}^{h}$ denotes the quantity of good $s$ purchased by sector $h$ at period $t$ for intermediate inputs and $B_{h}^{M}$ denotes the set of sector indices which are inputs to the production of good $h$. The weights are normalized to satisfy: $\sum_{s \in B_{h}^{M}} x_{s h}=1$ and $x_{s h}=\gamma_{s h} / \gamma_{h}$ where $\gamma_{s h}$ is the $s h^{\text {th }}$ element of $\Gamma_{m}$, the intermediate input-use matrix, denoting the cost share of total expenditure on intermediate goods in sector $h$ due to purchases of intermediate goods from sector $s$. And $\gamma_{h}$ denotes the sum of the $h^{\text {th }}$ column in $\Gamma_{m}$.

Further, capital is accumulated through an investment process given by

$k_{t+1}^{h}-\left(1-\mu_{h}\right) k_{t}^{h}=\eta\left(i_{t}^{h}\right)$

where $\mu_{h}$ is a sector specific depreciation rate. The (composite) investment good for sector $h$ is created by combining inputs in a Cobb-Douglas form:

$\eta\left(i_{t}^{h}\right)=\prod_{s \in B_{h}^{I}}\left(i_{t, s}^{h} \tilde{x}_{s h}^{\tilde{x}_{s h}}\right.$

where $i_{t, s}^{h}$ denotes the quantity of good $s$ purchased by sector $h$ for investment purposes and $B_{h}^{I}$ denotes the set of sectors from which sector $h$ purchases intermediate goods for capital investment. And the weight $\tilde{x}_{s h}$ is derived from the capital input-use matrix, $\Gamma_{I}$, similarly to the weight $x_{s h}$ in the index of intermediate inputs (3).

Now, in order to show that Hornstein-Praschnik (1997)'s two-sector (nondurables and durables) specification is a special case of the more disaggregated multisector specification, let $N$ and $D$ denote respectively the set of industrial sectors producing 
nondurable and durable goods. First of all, Hornstein and Praschnik (1997) assumes a reduced version of the production technology (1) such that the production of nondurable goods does not require intermediate input. That is, $\gamma_{h}=0$ in (1) so that

$y_{t}^{h}=A_{t}^{h}\left(k_{t}^{h}\right)^{\alpha_{h}}\left(n_{t}^{h}\right)^{\beta_{h}}$ for all $h \in D$.

Further, they simplified the sectoral intermediate input index (3) by assuming that the output of durable goods is not used as intermediate inputs in the production of both nondurable and durable goods: that is, $x_{s h}=0$ for all $s \in D$ in (3), which implies

$M_{t}^{h}=\prod_{s \in B_{h}^{M}}\left(m_{t, s}^{h}\right)^{x_{s h}}$ where $B_{h}^{M} \subseteq N$

The composite sectoral investment good is also simplified by assuming that the output of nondurable goods is not built into the capital stocks in the production sectors: that is, $\tilde{x}_{s h}=0$ for all $s \in N$ in (5), and hence

$\eta\left(i_{t}^{h}\right)=\prod_{s \in B_{h}^{I}}\left(i_{t, s}^{h}\right)^{\tilde{x}_{s h}}$ where $B_{h}^{I} \subseteq D$

In Hornstein and Praschnik (1997), the set of nondurable- and durable-goods sectors are respectively aggregated to a single sector each, which reduces the above specifications even further. That is, $y_{t}^{h}=A_{t}^{h}\left(k_{t}^{h}\right)^{\alpha_{h}}\left(n_{t}^{h}\right)^{1-\alpha_{h}}$ for $h \in N, y_{t}^{h}=A_{t}^{h}\left(k_{t}^{h}\right)^{\alpha_{h}}\left(n_{t}^{h}\right)^{\beta_{h}}\left(M_{t}^{h}\right)^{\gamma_{h}}$, $M_{t}^{h}=m_{t, s}^{h}$, for $h \in D$ and $s \in N$, and $\eta\left(i_{t}^{h}\right)=i_{t, s}^{h}$ for $h \in N, D$ and $s \in D$ which simplifies the law of motion of capital accumulation (4) to $k_{t+1}^{h}-\left(1-\mu_{h}\right) k_{t}^{h}=i_{t, s}^{h}$ for $h \in N, D$ and $s \in D$.

The consumer-shareholders allocate labor hours to the various industry sectors and make consumption-savings decisions. As in Hornstein and Praschnik (1997), the representative consumer seeks to maximize his or her discounted expected utility with indivisible labor given by

$E_{0} \sum_{t=0}^{\infty} \delta^{t}\left[\log C_{t}-\chi\left(1-L_{t}\right)\right], 0<\delta<1$ and $\chi>0$ 
subject to:

$$
\sum_{s=1}^{M} p_{t}^{s} c_{t}^{s}=\sum_{s=1}^{M} p_{t}^{n_{s}} n_{t}^{s}+\sum_{s=1}^{M}\left(d_{t}^{s}+q_{t}^{s}\right) s_{t}^{s}-\sum_{s=1}^{M} q_{t}^{s} s_{t+1}^{s} \equiv a_{t}
$$

In (6), $\delta \in(0,1)$ is a discount factor, $C_{t}$ is an aggregate consumption index, and $L_{t}$ is an aggregate leisure index at period $t$. Given an initial share $s_{0}^{s}$ for $s=1, \cdots, M$, the consumer's budget constraint (7) shows that the sum of goods purchased, $c_{t}^{s}$, valued at their respective prices, $p_{t}^{s}$ cannot exceed $a_{t}$, total income in period $i$. Other notations concerning sector $s$ at period $t$ are: $p_{t}^{n_{s}}$ hourly wage, $d_{t}^{s}$ dividend paid per share held, $q_{t}^{s}$ share price per unit, $s_{t}^{s}$ share holdings at the beginning of $t$, and $s_{t+1}^{s}$ shares purchased for period $t+1$.

The aggregate consumption index has a Cobb-Douglas form:

$$
C_{t}=\prod_{s=1}^{M}\left(c_{t}^{s}\right)^{\xi^{s}}
$$

where $\xi^{s}$ is aggregation weight. Further, the representative consumer is endowed with one unit of time in each period and the aggregate leisure index takes the following form:

$$
L_{t}=1-\sum_{s=1}^{M} n_{t}^{s}
$$

That is, labor hours are perfect substitutes for the consumer/worker, implying that the worker would devote all time to the sector paying the highest wage. Hence, at the margin, all sectors pay the same hourly wage.

\subsection{Competitive Equilibrium}

The competitive equilibrium consists of vectors of exogenous productivity shocks $\left\{\varepsilon_{t}\right\}_{t=0}^{\infty}$, price vectors $\left\{p_{t}, \pi_{t}, p_{t}^{n}\right\}_{t=0}^{\infty}$, and quantity vectors $\left\{k_{t}, n_{t}, M_{t}, c_{t}, i_{t}, y_{t}\right\}_{t=0}^{\infty}$ such that

1. productivity levels $\left\{A_{t}\right\}_{t=0}^{\infty}$ follow their laws of motion given by (2) subject to shocks $\left\{\varepsilon_{t}\right\}_{t=0}^{\infty}$;

2. firms maximize present discounted value of dividends $\left\{d_{t}^{h}\right\}_{t=0}^{\infty}$ subject to the sectoral production technology (1) and the sectoral law of motion of capital accumulation (4): 


$$
E_{0} \sum_{t=0}^{\infty} \delta^{t}\left(\frac{a_{t}}{P_{t}}\right)^{-1}\left(\frac{d_{t}^{h}}{P_{t}}\right)
$$

where $d_{t}^{h}=p_{t}^{h} y_{t}^{h}-p_{t}^{n_{h}} n_{t}^{h}-\pi_{t}^{h} \eta\left(i_{t}^{h}\right)-P_{t}^{M_{h}} M_{t}^{h}, \pi_{t}^{h}=\prod_{s \in B_{h}^{l}}\left(\frac{p_{s}^{h}}{\tilde{x}_{s h}}\right)^{\tilde{x}_{s h}}$ and $P_{t}^{M_{h}}=\prod_{s \in B_{h}^{\mu}}\left(\frac{p_{t}^{s}}{x_{s h}}\right)^{x_{s h}}$

3. consumers maximize lifetime utility (6) subject to:

$$
\sum_{s=1}^{M} p_{t}^{s} c_{t}^{s}=\sum_{s=1}^{M}\left[p_{t}^{n_{s}} n_{t}^{s}+r_{t}^{s} k_{t}^{s}-\pi_{t}^{s} \eta\left(i_{t}^{s}\right)\right] \equiv a_{t}
$$

where the wage rate $p_{t}^{n_{s}}=\alpha_{s} p_{t}^{s} y_{t}^{s} / n_{t}^{s}$ and the capital rental rate $r_{t}^{s}=\beta_{s} p_{t}^{s} y_{t}^{s} / k_{t}^{s}$;

4. prices clear labor markets and goods markets:

$$
\begin{aligned}
& n_{t}^{h}=\frac{\beta_{h}}{\chi} \frac{p_{t}^{h} y_{t}^{h}}{a_{t}} \\
& y_{t}^{h}=c_{t}^{h}+\sum_{s=1}^{M} i_{t, h}^{s}+\sum_{s=1}^{M} m_{t, h}^{s} .
\end{aligned}
$$

The competitive equilibrium in the two-sector (nondurables and durables) model of Hornstein and Praschnik (1997) can be obtained from the above definition by imposing the appropriate restrictions as elaborated in the previous section. Except for a special case of the parameter set, analytical solutions are not possible. An approximate solution is computed by log-linearizing all equilibrium equations with a first-order Taylor series expansion around the model's steady state.

\subsection{Calibration}

As for the calibrations of the model parameters, the level of sectoral disaggregation is set to $M=36$, following the sectoral definitions used by Jorgenson et al. (1987) which has a mixture of 1- and 2-digit SIC industries. The production technology parameters, $\alpha_{h}, \beta_{h}$, and $\gamma_{h}$ are set respectively as the time-series average of cost shares for capital, labor, and 
intermediate inputs for 36 sectors using annual data from 1948 to 1985 (Jorgenson et al., 1987) by dividing the cost of inputs by the value of output both evaluated at producer prices. The mean value of $\alpha_{h}$ across sectors is 0.16 , the mean value of $\beta_{h}$ is 0.32 , and the mean value of $\gamma_{h}$ is 0.52 . The "shocks" parameters, $\rho_{h}$ and $\Omega$, are also constructed using the Jorgenson data set. We consider the model economy where the productivity shocks are not independent across sectors: that is, off-diagonal elements from the estimated variance-covariance matrix of sectoral productivity residuals are not assumed to be zero.

The sectoral depreciation rates of capital stocks, $\mu_{h}$, are those used in Jorgenson et al. (1987).

The time period considered is the quarter year. Following the other business cycle models, the discount factor, $\delta$, is set to be $(1.03)^{-0.25}$ implying an annual discount rate of $3 \%$. The parameter $\chi$ is set so that total hours worked in steady state represent one-third of the worker's total time endowment. The share parameter $\xi^{s}$ in the aggregate consumption index is obtained from the nominal consumption expenditure share of sector $s$ in total consumption, $\xi^{s}=p^{s} c^{s} / \sum p^{s} c^{s}$, using consumption data from the National Income and Product Accounts.

Data for the investment-use matrix $\Gamma_{I}$ and the intermediate input-use matrix $\Gamma_{m}$ are based on the 1977 capital flow table described in Silverstein (1985) and the 1977 detailed intermediate input-use table, respectively. The capital-use and intermediate input-use tables are converted respectively to $\Gamma_{I}$ and $\Gamma_{m}$ by properly aggregating to 36 sectors and then dividing columns by their sums. The share parameter $\gamma_{s h}$ is obtained from $\gamma_{h}$ after being divided across all interacting sectors using the fraction that the purchases from these sectors represent out of total intermediate purchases by sector $h$.

\section{RESULTS}

The simulation results are presented in Table 1 . The second column reports the business cycle comovement of sectoral employment in the US, followed by their counterparts in the model economy. The comovement is measured simply by calculating correlation coefficients between the business cycle component of (quarterly) hours worked in a given sector and the business cycle component of total hours worked (quarterly). The hours worked in the US are based on the establishment survey data available in the DRI Economics database (formerly CITIBASE) covering from 1964 to 2000.

The correlation coefficients in the model economy are average statistics over 100 simulated economies of length 148 quarters. Both actual and simulated hours are HP (Hodrick-Prescott) filtered before they are used to estimate correlation coefficients.

The sectoral disaggregation level in the DRI database has some minor differences from Horvath (2000). For example, the DRI database does not cover agriculture and have the 
mining sector broadly defined including metal, nonmetallic, and coal mining. For those sectors whose definitions do not conform to Horvath (2000), the estimates of the business cycle comovement are as follows: transportation and public utilities (0.82), wholesale trade $(0.87)$, retail trade $(0.86)$, and services $(0.67)$. In order to compare with the twosector comovement results in Hornstein and Praschnik (1997), the disaggregated sectors are grouped into the nondurable and durable goods producing sectors following Hornstein and Praschnik (1997) definition of these two sectors. Notice that there is substantial business cycle comovement in the data. Only two relatively small sectors (tobacco manufactures and petroleum \& coal products) exhibit little tendency to move up and down with general economic conditions over the business cycle.

As reported in the third column ("Indivisible") in Table 1, the model simulations imply strong sectoral employment comovement over the business cycle. With the indivisiblelabor specification of preferences given by (6), there is no "leisure smoothing" in the sense that consumers do not care about the variability of leisure, and the business cycle comovement in employment is attributed to the intersectoral linkages due to the use of a sector's (nondurable or durable) output as intermediate inputs and/or capital inputs in the production of nondurables or durables. This can be verified from the following equation which determines a sector $h$ 's employment in equilibrium:

$n_{t}^{h}=\frac{\beta_{h}}{\chi} \frac{p_{t}^{h} y_{t}^{h}}{a_{t}}$ where $y_{t}^{h}=c_{t}^{h}+\sum_{s=1}^{M} i_{t, h}^{s}+\sum_{s=1}^{M} m_{t, h}^{s}$.

Notice that, for given $\beta_{h} \in(0,1)$ and $\chi>0$, sectoral employment $n_{t}^{h}$ depends largely on its output $y_{t}^{h}$ which can be used as intermediate inputs in the production sectors $\sum_{s=1}^{M} m_{t, h}^{s}$, or investment goods built into the capital stocks of the sectors $\sum_{s=1}^{M} i_{t, h}^{s}$, or final consumption goods $c_{t}^{h}$. At the disaggregated level of 36 industrial sectors, for example, both the intermediate input-use and the capital-use matrices imply sufficient intersectoral linkages to explain the sectoral employment comovement over the business cycle. Let $I^{h}$ denote the proportion of sector $h$ 's output that is either used as intermediate inputs for production or built into capital stocks. Then, from the goods-market clearing condition for sectoral output,

$I^{h}=\frac{\sum_{s=1}^{M} i_{t, h}^{s}+\sum_{s=1}^{M} m_{t, h}^{s}}{y_{t}^{h}}=1-\frac{c_{t}^{h}}{y_{t}^{h}}$

where $c_{t}^{h}=\frac{\xi^{h} a_{t}}{p_{t}^{h}}$ 
In the third column of Table 1, the sectoral averages of these numbers over 100 simulations are reported in the parentheses next to the corresponding sectoral employment comovement.

This is a generalization of Christiano and Fisher (1998)'s two-sector (consumption and investment) model where indivisible labor implies a constant employment in the consumption sector. This is mainly because they do not consider an intermediate input channel: that is, output from the consumption sector is not used as intermediate inputs for the production in the investment sector, and hence "output" and "consumption" in the consumption sector becomes identical. This implies that, in equation (10), $p_{t}^{h} y_{t}^{h}=p_{t}^{h} c_{t}^{h}=\xi^{h} a_{t}$ in the consumption sector, yielding a constant employment. Christiano and Fisher (1998) then have to rely on limited labor mobility and habit persistence for employment comovement. According to equation (10), when all the possible intermediate goods channels are considered, a constant employment with indivisible labor would be rather an exception in the sense that it occurs only to a sector whose output is never used as intermediate goods. Hence, without leisure smoothing on the part of consumers, the intersectoral linkages (as manifested by the intermediate inputuse and the capital-use tables) can account for the sectoral employment comovement over the business cycle without relying on additional restrictions such as limited labor mobility and habit persistence.

Christiano and Fitzgerald (1998) also argue against the intermediate input channel by noting strong business cycle comovement in subsectors of the nondurable-goods sector, despite the wide variation in the strength of each nondurable subsector's intersectoral linkage (including zero) with the investment sector. The strength of the intermediate input channel is measured as the fraction of a nondurable sector's gross output which is allocated to intermediate goods sent directly or indirectly for the production of final investment goods.

However, the intersectoral linkages as considered here are much broader in the sense that the model as in Horvath (2000) allows for the potential uses of a sector's (nondurable or durable) output as intermediate inputs and/or capital inputs in the production of nondurables or durables (including final investment goods). The implied strength of intersectoral linkages are therefore much larger than those in Christiano and Fitzgerald (1998).

Further, as reported in column 6 of Table 1, the intersectoral linkages are overall consistent with the investment comovement across sectors, although its size is still below what is observed in the US data.

\subsection{On the role of indivisible labor}

These findings are qualitatively similar to those in Hornstein and Praschnik (1997). They examine a two-sector (nondurable/consumption goods and durable/investment goods) model with indivisible labor where some of the output of the consumption-goods sector is 
used as intermediate inputs in the production of investment goods. In a boom, for example, the output in the consumption sector increases with the increased need for the output of the consumption good sector for use in the investment good sector.

However, in the context of a dynamic stochastic general equilibrium model, the sectoral comovement in employment depends crucially on the specification of preferences over leisure. For the utility function with divisible labor such as $U\left(C_{t}, L_{t}\right)=u\left(C_{t}\right)+v\left(L_{t}\right)$ where both $u(\cdot)$ and $v(\cdot)$ are increasing and strictly concave, the consumer's intertemporal consumption choice is determined by the following first-order condition:

$u^{\prime}\left(C_{t}\right) / P_{t}=\delta E_{t}\left[R_{t+1}^{h} u^{\prime}\left(C_{t+1}\right) / P_{t+1}\right]$

where $R_{t+1}^{h} \equiv \frac{d_{t+1}^{h}+q_{t+1}^{h}}{q_{t}^{h}}$

Substituting $v^{\prime}\left(L_{t}\right) / p_{t}^{n_{h}}=u^{\prime}\left(C_{t}\right) / P_{t}$ implied by the intratemporal consumption-leisure choice, the above equation can be rewritten as:

$v^{\prime}\left(L_{t}\right)=\delta E_{t}\left[R_{t+1}^{h} \frac{p_{t}^{n_{h}}}{p_{t+1}^{n_{h}}} v^{\prime}\left(L_{t+1}\right)\right]$

This implies intertemporal leisure smoothing in the sense that consumers prefer a less variable leisure. However, with indivisible labor or $v^{\prime}\left(L_{t}\right)=v^{\prime}\left(L_{t+1}\right)$ equal to some constant, the above equation implies that consumers choose leisure over time depending on the intertemporal price of current leisure without caring about the variability of leisure over time.

For example, the utility function of the form $U\left(C_{t}, L_{t}\right)=\log C_{t}+\chi \log \left(L_{t}\right)$ yields the following equilibrium condition for the sectoral employment:

$n_{t}^{h}=\frac{\beta_{h}}{\chi} \frac{p_{t}^{h} y_{t}^{h}}{a_{t}} L_{t}$ where $L_{t}=1-\sum_{s=1}^{M} n_{t}^{s}$.

Notice that, in the presence of "leisure smoothing", a given sector's labor hours are negatively related to hours worked in the other sectors. For an industrial sector having relatively weak linkages to the other sectors, its intersectoral linkages are more likely to be dominated by the "leisure-smoothing" effect, yielding a low or even a negative 
comovement in employment over the business cycle. For example, as illustrated in the fourth column ("Divisible") in Table 1, a version of the model with divisible labor implies some negative business cycle comovement as well as positive ones. The intermediate input-use and the capital-use tables indicate that the negative sectoral comovement occurs to those sectors having many zero elements in the intermediate input-use and capital-use matrices, meaning that their inputs in the production of the other sectors are trivial.

\subsection{Low substitutability of labor supply}

How can a divisible-labor model reconcile the sectoral employment comovement? Referring to the empirical studies in labor economics which find a relatively low wage elasticity of labor supply (e.g. Altonji (1982) and Ashenfelter and Altonji (1980)) and persistent wage differences across sectors, we simulate the model economy where elasticity of substitution of labor supply is relatively low across sectors. This is a way to capture persistent wage differences in the representative agent framework. The form of aggregate leisure index $L_{t}$ in the preferences is now generalized to allow for less-thanperfect substitutability of labor hours across sectors:

$L_{t}=1-\left[\sum_{s=1}^{M}\left(n_{t}^{s}\right)^{\frac{\tau+1}{\tau}}\right]^{\frac{\tau}{\tau+1}}, \tau>0$

As $\tau \rightarrow \infty$, labor hours become perfect substitutes for the consumer/worker as in Hornstein and Praschnik (1997), implying that the worker would devote all time to the sector paying the highest wage. Hence, at the margin, all sectors pay the same hourly wage. For $\tau<\infty$, hours worked are not perfect substitutes for the worker. The worker has a preference for diversity of labor, and hence would prefer working a positive number of hours in each sector even when the wages are different among sectors. Now, sectoral hours worked are determined by the following equilibrium condition:

$n_{t}^{h}=\left(\frac{\beta_{h}}{\chi} \cdot \frac{p_{t}^{h} y_{t}^{h}}{a_{t}} L_{t}\left(1-L_{t}\right)^{\frac{1}{\tau}}\right)^{\frac{\tau}{1+\tau}}$

Noting the typical finding in labor economics that wage elasticity of labor supply is relatively low, Horvath(2000) set $\tau=1$ to represent the worker's reluctance to substitute labor hours across sectors. As in the previous case of perfectly substitutable labor hours across sectors, the parameter $\chi$ is set so that total hours worked in steady state represent 
one-third of the worker's total time endowment. For example, $\tau=1$ implies $\chi=13.4$. The last two columns in Table 1 illustrate that a low elasticity of substitution of labor across sectors (e.g. $\tau=1$ ), implying the low wage elasticity of labor supply, can generate the strong business cycle comovement of sectoral hours worked. Therefore, in the presence of leisure smoothing, the intermediate channel alone is not sufficient to generate the strong business cycle comovement across sectors: it further requires some form of worker's reluctance to substitute labor hours across sectors.

\section{CONCLUDING REMARKS}

We have studied a multisector dynamic stochastic general equilibrium model calibrated to the 2-digit SIC level intermediate input-use and capital-use tables to investigate the importance of the intermediate input channel in explaining the sectoral employment comovement over the business cycle. In general, the business cycle comovement in employment depends on the specification of preferences as well as technology with potential intersectoral linkages. With indivisible labor or no leisure smoothing on the part of consumers, the intersectoral linkages at a disaggregated level are sufficient to generate the strong business cycle comovement across sectors. With divisible labor, however, leisure-smoothing effect can dominate a sector's intersectoral linkage, implying a negative comovement. It further requires some form of worker's reluctance to substitute labor hours across sectors. Referring to some micro-level studies on the low wage elasticity of labor supply, a low substitution of labor hours is shown to generate the strong business cycle comovement in sectoral hours worked.

\section{REFERENCES}

Altonji, J.G., The intertemporal substitution model of labor market fluctuations: an empirical analysis, Review of Economic Studies, 49:783-824, 1982.

Ashenfelter, O. and J.G. Altonji, Wage movements and the labor market equilibrium hypothesis, Econometrica, 47, 217-245, 1980.

Boldrin, M., L.J. Christiano, and J.D.M. Fisher, Habit persistence, asset returns and the business cycle, American Economic Review, 91(1), 149-166, 2001.

Christiano, L.J. and J.D.M. Fisher, Stock market and investment good prices: implications for macroeconomics, working paper, Federal Reserve Bank of Chicago, 1998.

Christiano, L.J. and T.J. Fitzgerald, The business cycle: it's still a puzzle, Economic Perspectives, Federal Reserve Bank of Chicago, 1998.

Horvath, M.T.K., Sectoral shocks and aggregate fluctuations, Journal of Monetary Economics, 45, 69-106, 2000. 
Horvath, M.T.K., Cyclicality and sectoral linkages: aggregate fluctuations from independent sectoral shocks, Review of Economic Dynamics, 1, 781-808, 1998.

Hornstein, A. and J. Praschnik, Intermediate inputs and sectoral comovement in the business cycle, Journal of Monetary Economics, 40: 573-595, 1997.

Huffman, G. and M. Wynne, The role of intratemporal adjustment costs in a multisector economy, Journal of Monetary Economics, 43, 317-350, 1999.

Jorgenson, D.G., F.M. Gollop, and B. Fraumeni, Productivity and US Economic Growth, Harvard University Press, Cambridge, 1987.

King, R.G., C.I. Plosser, and S. Rebelo, Production, growth and business cycles: I. the basic neoclassical model, Journal of Monetary Economics, 21, 1988.

Kydland, F. and E.C. Prescott, Time to build and aggregate fluctuations, Econometrica, 50, 1345-1370, 1982.

Long, J. and C.I. Plosser, Real business cycles, Journal of Political Economy, 91, 39-69, 1983.

Phelan, C. and A. Trejos, On the aggregate effects of sectoral reallocations, manuscript, Northwestern University, 1996.

Ramey, V. and M. Shapiro, Displaced capital, National Bureau of Economic Research Working Paper, No. 6775, 1998.

Silverstein, G., New structures and equipment by using industries, 1977, Survey of Current Business, 65, 26-35, 1985. 
Table 1. Cross-sectoral business cycle comovement

\begin{tabular}{|c|c|c|c|c|c|c|c|}
\hline \multirow{2}{*}{ Sector } & \multicolumn{4}{|c|}{ Employment } & \multicolumn{3}{|c|}{ Investment } \\
\hline & US Data & Indivisible & Divisible & $\tau=1$ & Indivisible & Divisible & $\tau=1$ \\
\hline \multicolumn{8}{|l|}{ Nondurables \& Services } \\
\hline Agricultural products & & $0.94(0.93)$ & -0.89 & 0.99 & 0.09 & 0.03 & -0.04 \\
\hline Agricultural services & & $0.75(0.53)$ & -0.17 & 0.99 & 0.16 & 0.13 & -0.02 \\
\hline Metal mining & & $0.74(0.59)$ & 0.43 & 0.97 & 0.34 & 0.24 & 0.24 \\
\hline Coal mining & & $0.96(0.63)$ & 0.85 & 0.99 & 0.06 & 0.02 & 0.03 \\
\hline Petroleum \& natural gas & & $0.94(0.87)$ & 0.49 & 0.99 & -0.19 & -0.37 & 0.03 \\
\hline Nonmetallic mining & & $0.54(0.47)$ & 0.06 & 0.99 & 0.24 & 0.17 & 0.18 \\
\hline Construction & 0.89 & $0.29(0.96)$ & 0.09 & 0.95 & 0.26 & 0.19 & 0.32 \\
\hline Food \& kindred products & 0.62 & $0.98(0.41)$ & -0.97 & 0.99 & 0.1 & 0.05 & 0.001 \\
\hline Tobacco products & -0.0012 & $0.83(0.19)$ & -0.98 & 0.99 & 0.13 & 0.1 & -0.006 \\
\hline Textile mill products & 0.62 & $0.84(0.85)$ & 0.2 & 0.99 & 0.08 & 0.04 & -0.0002 \\
\hline Apparel & 0.64 & $0.58(0.26)$ & -0.61 & 0.99 & 0.07 & 0.01 & -0.04 \\
\hline Paper & 0.85 & $0.50(0.72)$ & 0.37 & 0.96 & -0.2 & -0.18 & 0.06 \\
\hline Printing \& publishing & 0.91 & $0.95(0.55)$ & 0.32 & 0.99 & 0.26 & 0.28 & 0.09 \\
\hline Chemicals & 0.84 & $0.93(0.74)$ & 0.56 & 0.99 & 0.41 & 0.41 & 0.46 \\
\hline Petroleum \& coal products & 0.086 & $0.88(0.62)$ & 0.36 & 0.99 & 0.2 & 0.14 & 0.26 \\
\hline Rubber \& misc. plastics & 0.86 & $0.96(0.69)$ & 0.81 & 0.99 & 0.36 & 0.35 & 0.48 \\
\hline Leather & 0.36 & $0.69(0.29)$ & -0.95 & 0.99 & 0.08 & 0.04 & 0.02 \\
\hline Transportation services & & $0.78(0.67)$ & 0.35 & 0.98 & 0.27 & 0.24 & 0.19 \\
\hline Communication services & & $0.78(0.56)$ & 0.51 & 0.99 & 0.01 & 0.04 & 0.37 \\
\hline Electric utilities & & $0.98(0.01)$ & -0.98 & 0.99 & -0.09 & -0.24 & -0.13 \\
\hline Gas utilities & & $0.98(0.84)$ & 0.94 & 0.99 & -0.03 & -0.14 & 0.01 \\
\hline Wholesale \& retail trade & & $0.95(0.27)$ & -0.27 & 0.99 & -0.24 & -0.36 & 0.06 \\
\hline Finance, insurance \& real estate & 0.58 & $0.71(0.96)$ & 0.5 & 0.95 & 0.18 & 0.18 & 0.53 \\
\hline Water \& sanitary services & & $0.98(0.57)$ & 0.75 & 0.99 & -0.3 & -0.44 & -0.12 \\
\hline Other services & & $0.97(0.45)$ & 0.29 & 0.99 & -0.26 & -0.29 & -0.22 \\
\hline \multicolumn{8}{|l|}{ Durables } \\
\hline Lumber \& wood & 0.75 & $0.68(0.78)$ & 0.34 & 0.98 & 0.27 & 0.2 & 0.33 \\
\hline Furniture \& fixtures & 0.84 & $0.59(0.05)$ & -0.83 & 0.99 & 0.19 & 0.18 & 0.04 \\
\hline Stone, clay, glass & 0.93 & $0.57(0.76)$ & 0.23 & 0.99 & 0.26 & 0.18 & 0.25 \\
\hline Primary metal & 0.88 & $0.94(0.94)$ & 0.87 & 0.99 & 0.07 & 0.14 & 0.26 \\
\hline Fabricated metal & 0.95 & $0.78(0.89)$ & 0.56 & 0.99 & 0.34 & 0.29 & 0.38 \\
\hline Non-elec. machinery & 0.87 & $0.70(0.93)$ & 0.55 & 0.91 & 0.01 & 0.03 & 0.26 \\
\hline Elec. machinery & 0.88 & $0.47(0.79)$ & 0.24 & 0.92 & 0.19 & 0.19 & 0.19 \\
\hline Motor vehicles & 0.62 & $0.49(0.49)$ & 0.42 & 0.92 & -0.12 & -0.08 & -0.01 \\
\hline Transportation equipment & 0.81 & $0.82(0.63)$ & 0.57 & 0.99 & 0.15 & 0.12 & 0.2 \\
\hline Instruments & 0.71 & $0.27(0.64)$ & 0.19 & 0.79 & 0.17 & 0.21 & 0.17 \\
\hline Misc. manufacturing & 0.88 & $0.59(0.50)$ & 0.45 & 0.94 & -0.2 & -0.22 & 0.02 \\
\hline
\end{tabular}


